\title{
ENVIRONMENTAL ELEMENTS AND THEIR SYMBOLIC MEANINGS IN SELECTED DRAMATIC AND FICTIONAL WORKS
}

\author{
Nahidh Falih Sulaiman, Ph.D. \\ Assist. Prof., Department of English, Faculty of Education for Humanities, Diyala University, IRAQ \\ nahidhum@gmail.com
}

\begin{abstract}
Symbolism, closely related to imagery, served to indicate an object or an idea. It is possible for the author to refer to the meaning indirectly when he believes his themes expressed eloquently by using symbols rather than by referring to the aim directly. In any literary topic, an author enhances the themes of his writing through using certain symbols to add more richness and color. Objects often used as indications to create meaning in a work. Throughout various forms of literature, environmental elements such as a lonely streetlight, tree, scarecrow, etc., help readers to understand and follow meaningfully the event sequences.

To shed the light on the significant use of some of the environmental elements, the paper includes two main parts; the first is concerned with some environmental elements discussed separately in two plays through sub parts while the second part discusses some other, environmental elements in two novels through sub parts. Each sub part stresses on a symbolic literary reference that differs in meaning but all devoted to define, at least, one essential theme.

The first part is mainly concerned with dramatic elements that presented in certain plays. The function of the "Dry trees" or "leafless trees" as a theme naturalistically devoted to explain poor emotions and lifeless meaning that obviously seen in Samuel Beckett's Waiting for Godot. This part also deals with the element of the "scarecrow" in Marina Carr's Women and Scarecrow. The second part is concerned with the use of "postbox" in waiting glimpses of hope in Alice Walker's The Color Purple. This part also sheds the light on the significance of the "windmill" in George Orwell's Animal Farm as the writer gave an alternative meaning for industrialization.
\end{abstract}

Keywords: Environmental Element, Spiritual inspiration, Fictional symbols, Dramatic Symbols

\section{FUNCTIONS OF ENVIRNOMENTAL ELEMENTS IN DRAMATIC WORKS}

Human already attempts to explain what may do around what is important to discuss through some sorts of working machines of contemporary tools such as note pad, but such tools determine simple and available ways to reflect what is in human mind. People try to understand what things that can ensure a definite connection among them. A leafless tree, scarecrow...etc can be traced easily in some dramatic works holding new interpretations in man's mind and memories. 


\section{A. A Leafless Tree and a Full Tree of leaves: Samples of a Conditional Hope and a Giver of Gifts}

Exploring the symbolism of tree is perhaps an inspiring way to learn set of life lessons. It is that nature element of how to live, grows, expand, change, and even die in terms of magnificence. It is a symbol of grace that has grace and patience of long-time standing and endurance. Cultures around the world evaluate trees when they referred to as the essence of infinite bestowal that teach endless lessons and give valuable meanings.

The meaning of the natural beauty of a tree goes beyond the significant details of that element in people lives as it goes beyond the mythological respect. Historically, tree branches indicate the entire energy of knowledge man gains in daily life. They nurture the spiritual development of human seeking truth and faith and celebrate people religious indications of their first existence. In a direct association, the tree demonstrates human physical being and touches the first entries of understanding and beginning. Yet, effectually, to connect with the meaning of tree existence, man joins the causes of creation and develops his knowledge about the rules of life. Among the significant meanings of trees is self-growth that explains human's desire to create life paths and powerful inner grounds profoundly and thoroughly in a loving way. The self-growth representation of trees symbolizes the fertility and the natural existence of various life elements including human beings. It is that balance between growth and nature difficulties when that growth needs strength and stability to stand firm within the life circle of challenges.

The tree occupies a significant role in various folk texts. For instance, in India, trees symbolize the sequence of human life seasons swaying the status of sorrow and joy, moving, and changing from birth, growth, and eventually death. To Indian folklore, the tree branches symbolize man's strives to reach the ends. Moreover, these branches with the buds are the ripen life activities of man and the re-creation of these energetic activities when trees shed dead leaves during winter and came back to life at another season by a clear hint to resurrection.

In a wider sense, trees are linking to immortality. It is the spiritual meaning of the self-recreation that accompanied by the seeds and fruits of the tree and man altogether. The immortal meaning in a living tree nurtures the relation between animate and inanimate elements of living. Both are the giver of gifts of unconditional love. Thus, the immortal and the immemorial fascinating parts of human life connected with nature and its elements of most generous mysteries.

In fiction, Zora Neale Hurston includes the pear true in her novel Their Eyes were Watching God (1937) to relate symbolically Janie's identifying moment to the sexuality of the springtime for that tree serves as Janie's standard of sexual and emotional fulfilment. In Hurston's novel, the pear tree mirrors the traditional gender stereotype. It symbolizes the female who waits passively the aggressive male bee who penetrates its blossoms. Therefore, the gender identity and the sexual fulfilment are interpreted by the mystical magic of a pear tree that symbolizes the patience and the lightness of spirit and words.

In Laurie Halse Anderson's novel Speak (1999), the protagonist Melinda was given the task of working with a tree as her object for the year in Mr. Freeman's art class. Yet, the tree symbolizes Melinda's spiritual growth that coincidentally Melinda and the tree share the dark surroundings and loneliness. But she could not stop reminding herself of how to finish her work journey with that tree and what this tree will look like. In Speak, Anderson creates close comparison between Melinda and the tree when the reflection of each is exchanged. Spiritual inspiration is taken exchangeably when the two are healthy or sick; "And the tree is sick. See how the branches on the left don't have any buds?"(Anderson 167). In terms of comparison, the dead branches are chopped off with the possibility for a new growth which seems the same kind of growth period in Melinda's life phases if she gets rid of the 'damage': “... those branches were long dead from disease. All plants are like that. By cutting off the damage, you make it possible for the tree to grow again...by the end of summer, this tree will be the strongest on the block" (Anderson 187).

The progress and growth in the tree life draw Melinda's ability to follow the same progress and psychological growing up personality to move past her rape. To go on maturely, Melinda has to realize that her tree is strong -rooted partner which holds a deeper meaning about life path although this tree has died after being struck by lightning, exactly the same situation when she thought that her life has stopped after her rape, yet never.

The body rooted in earth with the dancing leaves up the ground interprets the needs for a shelter and security. In Richard Wagner's play The Ring of the Nibelung (1876), the Oak tree is linking historically to Teutonic mythology. In the centre of Valhalla grew an oak tree, called Branstock, on which mistletoe grew. In this epic music drama, the oak formed the frames of their cottage homes and manor houses and for the navy 
that brought power to the British Empire" (Huckuale 8). Yet turning the oak tree into ashes means the end of the strength symbolically linked to the end of the empire. In Ring of the Nibelung, Wagner points to:

From the world ash-tree

Wotan then broke off a branch;

A spear-shaft

The mighty one cut from the trunk.

In the course of a long time

The wound laid waste the wood;

The foliage decayed and died:

The tree decayed and died. (quoted in Huckuale, 9)

"Wotan later piles logs from the World Ash" "yggdrasi" around Valhalla (Huckuale 8). So, the burning of the oak tree represents the end of power and the vanish of the source of that power, the gods. Oak tree as much of this epic drama refers to, is the environmental element of supernatural forces and danger of death as witches were hanged up. The concerns of power with the oak tree are seen through the sacrificial killing, supernaturalism, magic, moral meaning, and immortality.

Some interpretations of the leafless tree give various indications of a specific place. In Waiting for Godot (1953), Samuel Beckett signifies the natural element of the leafless tree to learn that Godot told the two men to wait for him by the willow tree. By focusing on themes such as harmony, strength, and rootedness to the soil, Beckett makes from that tree an integral part of the play rather than a decorous background. Estragon and Vladimir waited impatiently Godot to come to a place where "everything is dead but the tree" (Waiting for Godot 93) The negative indications of the waiting actually involve the two men themselves. The tree appears as the only echoing in the situation: Estragon: What is it?

Vladimir: It's the tree.

Estragon: Yes, but what kind?

Vladimir: I don't know. A willow. (Waiting for Godot 14)

In Waiting for Godot, the fallen state of man and life in the modern age symbolizes the fallen leaves of the willow tree. Although the tree stands for " the tree of Knowledge of Good and Evil, the tree of life, the cross,,.. the Judas Tree" (Graver 14). Thus representations of the tree behaves as if it mirrors the selfconscious of human's issues and ideas, and it seems a real philosopher then the play animate characters. Furthermore, the willow tree celebrates religious interpretations. In the Judeo- Christian tradition, such a kind of tree represents the wisdom and the promise of the renewal in life. The leafless symbol does not stop its effect as a source of uncertainty and raising questions for Estragon. Vladimir soon shared Estragon's wondering about the positive symbolic value of the tree. Yet, negatively, both point to it as the place where man hangs himself and as the term of despair leads to endless waiting. It might be interpreted as the gallows tree on which Christ was crucified in terms of hanging. Hence, death might be linked with that tree of fallen leaves when life has no hope or specific targets to reach. Death is a nether escape from waiting, and that waiting is no more than a defeat. Yet, generally, the half-lifeless tree indicates the long-passing time when waiting nothing is more than enjoying life.

\section{B. Scarecrow: The Dramatization of Security and Death}

In many cultures, scarecrow represents the harvest season. It is formed in the shape of a man, dressed in old ugly clothes hung to frighten away predators and birds. Historically, the scarecrow dates back to 712 Japan known as "kuebiko", as an omniscient creature. For thousands of years, people guarded their fields by using scarecrows from flock of scavengers. In addition, in Egypt, scarecrow used to frighten the flocks of quail. In Greece, people regularly used wooden scarecrow similar to Priapus, the son of Dionysius and Aphrodite. While in the Middle Ages, European people believed that scarecrow is full of power functions to bring fear to bad things. Thus, in Italy, special animals' skulls placed on the crops inside the field for scaring away the predators. To Germans, making wooden witches and placing them in the middle of the fields in winter as a perfect way to get rid of the evil energy and to allow spring to come pleasantly. While in the North America, people functioned their specific tools to scare the predators by behaving as live bird scaring and shouting in a horrible way. Those Native Americans tended to live during the Autumn seasons in huts and then turn their roles to protect the crops from animals and birds. 
Given a clear explanation of the scarecrow nature element is encouraged within the analysis of literary texts, specifically in drama when scarecrow is seen as more than a device but a character of important function.

In Ichundlch, a tragedy in six acts written in 1941 in Jerusalem by Else Lasker-Schuler, the scarecrow is connected to the evil of the modern age. Ichunlch figures out the postmodern theatre and uses elements that present the Nazi presence. Schuler, expelled from Germany, established in his exile a special world as a theatre that celebrates subjects of how to descent values from heaven to hell. In this play, the playwright combines violence and comedy juxtapose. The scarecrow is the Nazi National Socialist who scares people by death and violence and who lives "in the realm of the devil, Hell" (Colvin 143). While the comic scenes are represented by the Nazis' drunken robbery, singing: "Ich allein ja ich allein bin ein Teufel comme il faut!" (Colvin 143). Hence, the scarecrow is no more than the devil acts closely to the devil's role.

In 2006, Marina Carr published her first play Woman and Scarecrow to be performed at Irish Repertory Theatre. Carr analytically presents the state of a person who he/ she closely comes to death. Darkness inhabits people's minds the moment they start to fell down to their fatal ends. The flow of negative memories performs largely in a grim and pessimistic short life phase. The death of Woman brings a creative illusion of bad happenings and the reflection of life review. The Woman is very near to the end. Her ravaged body accompanied by scarecrow to function as the Woman's ego. The Scarecrow might be also the Woman's hallucination or her guardian angel. She represents a reminder of the passing-life events as well as the Woman's observer of the latter's history.

Carr cleverly implies to make the Scarecrow as a beast waits the rotten flesh to devour it. It was not only that source of fear, but rather it is fear that causes death. The Scarecrow is no more than the Woman's terrible life journey and her unfulfilled needs and achievements as she lived this unfulfillment with her husband. In a full realization, Woman stops her long-standing conflict with life hard times and the scarecrow ends that conflict to death advantage. To Carr, the dark side of the scarecrow refers to the darkness overwhelms Irish land under colonialism and the Woman's long-standing conflict is bitterly linked to the long-standing conflict of Ireland under the British rule.

The dramatization of the troubles happened in Northern Ireland is focused on by Carr when the latter mirrors the dark life of Irish people in terms of the lost identity. Thus, the depressed woman refers to the depressed nation. The Woman is left alone. She has none of her family members, friends' relations, or children. She faces her end completely alone. She is abandoned by her eight children and her unfaithful husband:

Woman: I've always known it. From the start I know this man is no good for me.

Scarecrow: And you went a head

Woman: yes I did.

Scarecrow: Why?

Woman: Because my dress was made and everyone was made and everyone was invited-Maybe I felt sorry for him.

Scarecrow: Because you felt sorry for him you had eight children.

\section{(Woman and Scarecrow Act II)}

In a very different way, the scarecrow is devoted to guard a land from predators and enemies, yet Carr invites her audience to reverse the role of it. In Woman and Scarecrow, Scarecrow signifies human's fear and death. It symbolizes the soul taker of godless life:

Woman: And how am I doing on the peaceful scale? On the fear gauge?...Well, l'll meet them when I meet them. At least the terrors of the earth are over. It can't be worst than here...can it?

Scarecrow: you don't want to know.

Woman: You can't wait to fly off, dump me in the grave. Fly off with him.

Scarecrow: I assure you I have no desire to fly off with that thing in the wardrobe. I

Promised you l'd settle you into your grave... 
Woman: Then why am I afraid to close my eyes?

Scarecrow: Close them, I'll watch.

Woman: You'll sneak away.

Scarecrow: Trust me

Woman: I need to sleep. Promise me you'll stand guard

Scarecrow: I told you

Woman: Lie here beside me, hold my hand

Scarecrow: Don't be such a coward.

Woman: And if I don't wake?

Scarecrow: You will wake

(Woman and Scarecrow Act II)

As the title suggests, Carr's play based on a dialogue between the unnamed woman of unrevealed malady and her imaginary alter ego, Scarecrow. Living the last moments of woman's life is the reason why Scarecrow stands beside her and waits impatiently to engrave the Woman's body and eventually to guard the soul there. Death is linked to Scarecrow's role that is available in wardrobe. It is linked also to the sharpbeaked black bird, raven or crow. However, despite the name, Scarecrow doesn't scare away the death bird and nor frightens death. It holds no virtues and offers no security. Scarecrow might be the hidden inner part of a self and its mirror that reflects the realistic image of human kind. Supposedly, Scarecrow finalizes the grim picture of marriage and the lack of opportunities to live happily. It is sight of one's selfhood.

\section{FUNCTIONS OF ENVIRONMENTAL ELEMENTS IN FICTIONAL WORKS}

Every detail written on a piece of paper and often is sent by a letterbox which is small in piece but big in meaning. Yet, generally, a written letter has a code information human prefers to use and function to ease what distance makes hard to link. Thus, letters initially sent and received through postbox as well.

Postbox had the same role of the machines of nowadays as the time passes more complicated and hard to manage with the speed of action and the accuracy of achievements. Yet, decoding messages sent by postbox and replied back by it had an emotional and spiritual meaning of waiting a hope comes from far away, or fatal tidings that may change life details. Simply, communicating by using artificial intelligence does change the belief in sweet simplicity in sending and receiving of the past years with an emphasis that the computer language is unable to represent fully the human minds and thoughts.

It seems more likely that postbox is not programmed to fit the answers when thoughts are reflected by handwriting. What actually man means is subject to argue if he/she writes verse or some sentimental lines believing that the thoughts and emotions get the happiness when the chances of inserting symbols are more available. Hence, no machine could feel of happiness, anger, sorrow, grief, or longing, and the charming of conveying these feelings lies when the minds like to saying everything the machine cannot transform or feel.

Although the development of technology takes a huge part in human life, thoughts and activities, yet spiritual symbols of humanly connection are irreplaceable. The age of spiritual letters could interpret moods and racial expressions to true humans. Historically, letterboxes or postboxes were found during the Victorian age by British people to take place in most houses front door. They were designed to insert letters through a simple slot with a flap over it. They were also planned to put them in the roadside of British Isles during 1852.

A smile may be created when a receiver gets a stamped letter that comes through the rural letterbox coming from the universal space. In "An Unstamped Letter in Our Rural Letter Box", Robert Frost describes the lovely smile he got regardless to spaces:

There I elected to demur

Beneath a low-slung juniper

That like a blanket on my chin

Kept some dew out and some heat in,

Yet left me freely face to face

All night with universal space.

(quoted in Juten 342) 
Frost depicts the memories of his own represented by a tramp through sleeping overnight on a farmer's land to see two falling stars falling together (Juten 342). The falling stars signify how thoughts are original and unexpected and how that man faces things face to face in villages and fields, which are completely rural stamped by unstamped letters hidden in a letterbox. Frost chooses the rural setting and connected it with one of the environmental symbol of a letterbox existed to connect people's emotional perspectives. Moreover, Frost's thoughts and inner feeling were set in a situational place of letters when sleeping, brain, and memories are able to quiver through moving, shaking, and kissing:

Inside the brain

Two memories that long had lain

Now quivered toward each other, lipped

Together, and together slipped.(quoted in Juten 342)

\section{A. Alice Walker's The Color Purple: A Creative spirit through the Postbox}

Alice Walker demonstrates the unusual way of exchanging tidings when emotions and needs were written but never said. In her novel The Color Purple (1982), Walker responds to human expressive feeling through mainly depending on the epistolary novel. The characterization of the postbox in the novel makes the cope with letters is essential in that the container of these letters represents a survival strategy to connect the protagonist Celie with her sister Nettie. Letters covered by the postbox symbolizes the writer's innovative way to link Celie with the environments of the southern population as well as the well-educated sister. Celie's mental shift from emotional aphasia to the responsible third person narrator was facilitated by writing letters that for many years written but not read. To Walker, the postbox metaphorically is Celie's heart that hides her secrets and feelings. It weaves the expressive art of Walker and skilful record of Celie's personal promises of creativity and overcoming.

The activity of writing letters and the characterization of the postbox represent the metaphoric migration of thoughts and inner feelings from oppressed spirit to the respondent who is incredibly long to read what that twin-spirit sister recorded.

The postbox is Walker's image space that replaces the negative encounter between Celie and Nettie. It is what the characters do otherwise when choices are limited to no way but an iron tool container of letters. Celie's letters serve as the turning point in discovering what is going on in life (Bona 52). Her letters should find an environmental content as her identity in searching for a social place. Moreover, Walker's postbox reveals the way of addressing God, as to Celie, was the simple and significant way to reflect her spiritual needs and collapse. As long as God is the addresses, the postbox might not be opened physically. On the other hand, Nettie's discovered letters that were stolen by Albert is the clarification of how that roadside postbox changes the events and the life lines of Celie when destiny plays its part positively and successfully through a passionate sisterly meeting between Celie and Nettie years later.

The woven writing Celie established and the epistolary novel Alice Walker adopted document the appreciative written dialogue relationship by the postbox allegorical role. Nevertheless, the environmental dimension of the postbox keeps it as a reminder of the unlimited and infinite way to communicate. Such a sort of communication spiritualized another communicating letters with God when He reads, listen, sees, and feels without a device. Moreover, the textile narratives of both Walker and her protagonist explore the influential role of certain concrete tools such as enveloped letters or postbox in the manifestation of the story telling and producing. Hearts are open when the postbox is ready to be opened and used frequently. Hence, Celie's medium of revelation repeats her desire to open what is closed and hidden severely by her husband and what is raped physically and spiritually by her stepfather .Celie in fact is praying, telling, complaining, contemplating, and winning by her written letters in the postbox.

The forced separation between Celie and Nettie is Walker's talented approach to shape that suffering with the awakening notes of postbox the readers and viewers should pay a serious attention to self-expression is determined the moment when the two sisters reunited asking if these letters were ever read or even discovered in the postbox. Thus, walker does not stop referring to the significance of writing letters and putting them in their place when individual interaction searches a tool or a placing situation to reveal emotions and feelings. So, literally and figuratively, the postbox is created to bring comfort and homage back memories of the two sisters that walker intelligently dramatizes the sense of self-expression fictionally. 


\section{B.Windmill: A Symbol of Harmony between Old English Life and the Rural Surroundings}

It is that symbol of classic English life when its wooden shape mingled in a perfect harmonies relation with the rural environment. It had that pleasing view on the hilltop or in the valley to move eyes looking towards what is often centre of attraction. Robert Louis Stevenson mirrors the beauty of windmill in his memories The Foreigner at Home:

There are indeed, few merrier spectacles than that of many windmills

bickering together in a fresh breeze over a woody country; their halting

alacrity of movement, their pleasant business, making bread all day

with uncouth gesticulations, their air, gigantically human, as of a creature

half alive, put a spirit of romance into the tamest landscape(Stervenson 181).

Walter Rose in his book The Village Carpenter; The Classic Memoir of the Life of a Victorian Craftsman(1937) recalled some of the romance details when he was a master carpenter and the son of carpenters in Victorian England. He symbolizes the windmill as that wings sail almost in sixty feet in the air:

The sails always reached to about two feet from the ground, and

it was an enthralling experience to stand before them- as I often did

when a stiff wind was blowing, and watch them go roaring by: to

note the "swoop", "swoop" of each sail as it passed and to follow

the orbit of one as it rose to almost sixty feet in the air, immediately

to descend and swiftly pass again.(Rose)

To Rose, windmill stands watching new wind is roaring and blowing. It rushes up hill-top and gets down dale in the countryside in wonderful scenery. It starts working with dawn and until black night ends up a day. It is that dancing mill brought joy and the wealth for the countryside people. The arm-sails is symbolized by rural men as the pine-tree that cannot give up its charity. Mostly, windmill is linked with yesteryears. Melancholy, it is represented by many poets as a decayed symbol of the prevailing moral and social system. They regretted how time engraved it since it was the hearts' content of Europe. For example, Robert Bridges describes the miller in his short poem "the Windmill":

The green corn waving in the dale,

The ripe grass waving on the hill:

I lean across the paddock pale

And gaze upon the giddy mill.

Its hurtling sails a mighty sweep

Cut thro' the air: with rushing sound

Each strikes in fury down the steep,

Rattles, and whirls in chase around.

Geside his sacks the miller stands

On high within the open door :

A book and pencil in his hands,

His grist and meal he rechoneth o;er. (Bridges)

To Bridges, the miller is another environmental figure who stands to work and live the reality of life. It is the scenery living situation when moves, lights, laughter, work, smoke, and seasons duty are all gathered and described by a miller whom he was described also by Alfred Lord Tennyson in his poem "The Miller's 
Daughter":

I see the wealthy miller yet,

His double chin, his portly size,

And who that knew him could forget

The busy wrinkles round his eyes.(Tennyson 93)

Many other pots sang the beauty of the countryside windmill in their poetry such as "who Has Seen the Wind?" by Christina Rosseti, "Five Eyes" by Walter de La Mare, and " Adventurous Love and other Verses" by Gilbergt Cannon.

Windmill had given very special attributes picturing it as that giant creature of four or five eyes. It is the symbolic calmness and the idle way of life when the slumbering landscape embraces it aesthetically. Novelists and poets stress on the fact that the bustling world of industry polluted the fairness of that "standing lady" in the middle of the grass.

In prose, windmill appears in various literary works such as in Miguel de Cervantes novel Don Quixote. In one of Don's adventures, he imagines the sail of a group of windmills to be the moving arms of giants. That scene permitted the revealing idiom of tilting at windmills that means the attacking imaginary enemies. The idiom refers to the confrontation with foe when are understood by others incorrectly, or the action of fight with the enemy was based on misunderstanding romantic or idealistic justifications. Windmill also appears in Shakespeare's play Henry IV, part I, Act 3:

But marked him not a word. $O$ he is as tedious

As a tired horse, a railing wife,

Worse than a smoking house. I had rather live

With cheese and garlic in a windmill, far (Shakespeare, 15 , quoted in Bevington)

There is no doubt that the windmill wears its 'modern garment' in modern age of some modern novelists such as Georg e Orwell. In Animal Farm (1945), Orwell signifies windmill to serve the industrial 'Five-year plan' of Stalin who aimed to improve Soviet Union industry for the benefit of proletariats. The windmill is functioned to represent the Soviets' attempts to develop their nation in terms of economy. Mainly, the idea of building a windmill is linked with Stalin's insistence to establish the country on powerful economy system of industrialized. Yet, Orwell presents Snowball, the main pig, to build the windmill in a symbolic way of modernism. Through a full recognition, the windmill was no more than the wasting time and effort rather to enhance people's ways and standard of living. On the other hand, the windmill of the modern age symbolizes the false promises of false leaders. The windmill equalizes Stalin's promises so easily to be shaken and fallen. Its falling represents the wasting efforts of others to dream in good living as it was blown down during a storm because shoddy materials like the fragility of Stalin's industrial dreams built it. Yet, Boxer, the strong horse, in the Animal Farm decided to rebuild the windmill for the five-year plans but the final destruction of the windmill because known as "The Battle of windmill" which Orwell functioned it to portrait the real-life Battle of Stalingrad.

Through the absence of romantic exploration of the windmill, that was clearly referred to in classic Europe, Orwell connected the symbol of the windmill with the increasing productivity of the modern age. Yet, the two pigs, snowball and Napoleon, differed in the significance of this symbol. Napoleon opposes the windmill:

One day, however, he arrived unexpectedly to examine the plans. He walked heavily round the shed, looked closely at every detail of the plans and snuffed at them once or twice, then stood for a little while contemplating them out of the corner of his eyes; then suddenly he lifted his leg, urinated over the plans, and walked out without uttering a word.

\section{(Animal Farm 80)}

Stories built on windmill became the serving tales of heritage and home. It represents the icon of beauty and the idea of everlasting existence of human romance. It saws wood for building homes. It captures the energy of air. It crushes grains for food and a place that gathers town people to do manual work and to share stories of the folk. It centres people to speak in arts and to sing for the possibilities of the coming future.

\section{CONCLUSION}

Literature gives an inspiring importance to the natural elements that significantly used in literary pieces. The 
role played by these elements is highly considered when qualities, thoughts, and ideas are interpreted symbolically. The literary analysis is thought to be more effective when it is built on using metaphors and allegories to discover meanings in the outer world. It became obvious from the symbolic studies that targeting several human values passes successfully when these values and ideas are explained and accompanied by some environmental factors. Through imagery and metaphor, a writer, especially playwrights and novelists, can fundamentally change the formation of his society thoughts and appreciation through showing much familiarity with the vital role of these symbolic elements. Accordingly, through literary analysis, leafless tree, scarecrow, postbox and windmill have been reviewed as elements for literary indications that overwhelm the event consequences of various literary genres.

\section{REFERENCE LIST}

Anderson, Laurie Halse.(1999).Speak. New York: Farrar Straus Giroux.

Beckett, Samuel.(1954).Waiting for Godot. New York : Grove press.

Bevington, David (ed).(1987). William Shakespeare: Henry IV, Part I. Oxford: Oxford University Press.

Bona, Mary Jo.(2015).Women Writing Cloth: Migrating Fictions in the American Imaginary. Lexington Books.

Bridges, Robert.(1890). The Shorter Poems of Robert Bridges. Berkeley: University of California.

Carr, Marina.(2014).Woman and Scarecrow. London: Faber and Faber.

Colvin, Sarah.(2003).Women and German Drama: Playwrights and their Texts, 1860-1945. Camden House: Boydell and Brewer Inc.

Graver, Lawrence.(2004). Beckett: Waiting for Godot. Cambridge: Cambridge University Press.

Huckuale, David.(2018) A Green and Pagan Land: Myth, Magic and Landscape in British Film and Televesion. North Carolina: McFarland and Company, Inc., Publishers Jefferson.

Juten, Naney Lewis and John Zubizarreta (ed).(2011). The Robert Frost Encyclopedia. London: Greenwood Publication Group.

Orwell, George.(1989).Animal Farm: A Fairy Story. Houghton: Mifflin Harcourt.

Rose , Walter.(2006). The Village Carpenter: The Classic Memoir of the Life of a Victorian Craftsman.Fresno,CA: Linden Publishing, Inc.

Stevenson, Robert Louis.(1914). The Novels and Tales of Robert Louis Stevenson: Vitginibus puerisque. The New York Public Library. Bequest of John L. Cadwalader, LL.D.,

Tennyson, Alfred Lord.(1892). The Works of Alfred, Lord Tennyson. Volume I. Boston and Vew York: Houghton, Mifflm and Company, Cambridge University. 